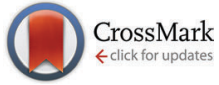

Cite this: Phys. Chem. Chem. Phys., 2016, 18, 14782

Received 9th April 2016,

Accepted 10th May 2016

DOI: $10.1039 / c 6 c p 02364 a$

www.rsc.org/pccp

\section{Surface modification of battery electrodes via electroless deposition with improved performance for $\mathrm{Na}$-ion batteries $\dagger$}

\author{
Abhishek Lahiri,* Mark Olschewski, René Gustus, Natalia Borisenko and \\ Frank Endres*
}

\begin{abstract}
Sodium-ion batteries (SIBs) are emerging as potential stationary energy storage devices due to the abundance and low cost of sodium. A simple and energy efficient strategy to develop electrodes for SIBs with a high charge/discharge rate is highly desirable. Here we demonstrate that by surface modification of $\mathrm{Ge}$, using electroless deposition in $\mathrm{SbCl}_{3}$ /ionic liquids, the stability and performance of the anode can be improved. This is due to the formation of $\mathrm{Ge}_{x} \mathrm{Sb}_{1-x}$ at the surface leading to better diffusion of $\mathrm{Na}$, and the formation of a stable twin organic and inorganic SEI which protects the electrode. By judicious control of the surface modification, an improvement in the capacity to between $50 \%$ and $300 \%$ has been achieved at high current densities $\left(0.83-8.4 \mathrm{~A} \mathrm{~g}^{-1}\right)$ in an ionic liquid electrolyte $\mathrm{NaFSI}-\left[\mathrm{Py}_{1,4}\right] \mathrm{FSI}$. The results clearly demonstrate that an electroless deposition based surface modification strategy in ionic liquids offers exciting opportunities in developing superior energy storage devices.
\end{abstract}

Sodium-ion batteries (SIBs) have recently received significant attention in the battery community for large scale energy storage needs due to abundant availability and low cost of sodium. ${ }^{1-3}$ For SIBs, the potential anode materials are Ge, Sn and Sb which have a theoretical capacity of 369,847 and $660 \mathrm{~mA} \mathrm{~h} \mathrm{~g}{ }^{-1}$, respectively. ${ }^{4-7}$ Alloys of these materials have also been shown to be promising anode materials. ${ }^{8-13}$ However, during cycling, all of them show reduced capacity retention primarily due to slow solid-state diffusion of $\mathrm{Na}$ ions, unstable solid electrolyte interface (SEI) formation and volume expansion/pulverisation. For example, in the case of germanium thin film anodes, the capacity declined rapidly after 20 to 30 cycles even at low charge/discharge rates of $\mathrm{C} / 10$ which has been related primarily due to the change in thin films to a porous morphology or fragmentation of thin films during cycling. ${ }^{14,15}$ To overcome this issue, we have developed a strategy involving judicious surface modification to produce

Institute of Electrochemistry, Clausthal University of Technology, Arnold-Sommerfeld-Str. 6, 38678, Clausthal-Zellerfeld, Germany. E-mail:abhishek.lahiri@tu-clausthal.de,frank.endres@tu-clausthal.de

$\dagger$ Electronic supplementary information (ESI) available. See DOI: 10.1039/c6cp02364a desired effects on both stability and capacity retention at relatively high charge/discharge current densities.

Surface modification is a versatile technique which has been shown to improve the structural stability, electronic and ionic conductivities as well as suppress surface reactions of the anodes and cathodes for lithium ion batteries. ${ }^{16-19}$ Various techniques have been applied for surface modification such as sputtering, atomic layer deposition (ALD), sol-gel coating, and mechanical coating, all of which require additional steps as well as additional energy for electrode development. ${ }^{17,19}$ In comparison, electroless deposition via galvanic displacement reaction does not require any external energy and the surface modification is triggered by a redox reaction. Until now, electroless deposition of noble metals has been used only in lithium-ion batteries to improve the electronic conductivity of anodes such as silicon which was performed in the presence of $\mathrm{HF}^{20-22}$ It was also found that only after heat treatment of the noble metals on silicon, the capacity fade could be reduced due to the formation of an alloy at the interface. $^{20}$

Here, we show the surface modification of the electrodeposited amorphous Ge thin film using electroless deposition in a $\mathrm{SbCl}_{3}$ /ionic liquid (IL) containing electrolyte to form $\mathrm{Ge}_{x} \mathrm{Sb}_{1-x}$ at the surface. Fig. $1 \mathrm{a}$ and $\mathrm{b}$ show the microstructure of the electrodeposited Ge and Ge modified in $0.1 \mathrm{M} \mathrm{SbCl}_{3}$-1-butyl-3methylpyrrolidinium bis(trifluoromethylsulfonyl)amide $(0.1 \mathrm{M}$ $\left.\mathrm{SbCl}_{3}-\left[\mathrm{Py}_{1,4}\right] \mathrm{TFSI}\right)$ by electroless deposition. A change in open circuit potential (OCP) was noted (Fig. S1, ESI $\dagger$ ) indicating the electroless deposition of $\mathrm{Sb}$ on Ge. However, repeated experiments showed that the change in OCP is not always identical as evident from Fig. S1 (ESI $\dagger$ ) and can arise due to the difference in reaction kinetics. The electrodeposited germanium forms a clustered and porous deposit having a cluster size of about 200-300 nm, Fig. 1a.

The Ge clusters are made up of small Ge nanoparticles in the size range of 30-50 nm which has been shown previously. ${ }^{23}$ The EDX of the electrodeposited Ge (Fig. S2a, ESI $\dagger$ ) shows a prominent peak of Ge. Besides, the peaks of $\mathrm{O}, \mathrm{S}$ and $\mathrm{Cl}$ are also seen which is due to exposure of the sample in air during the transfer 

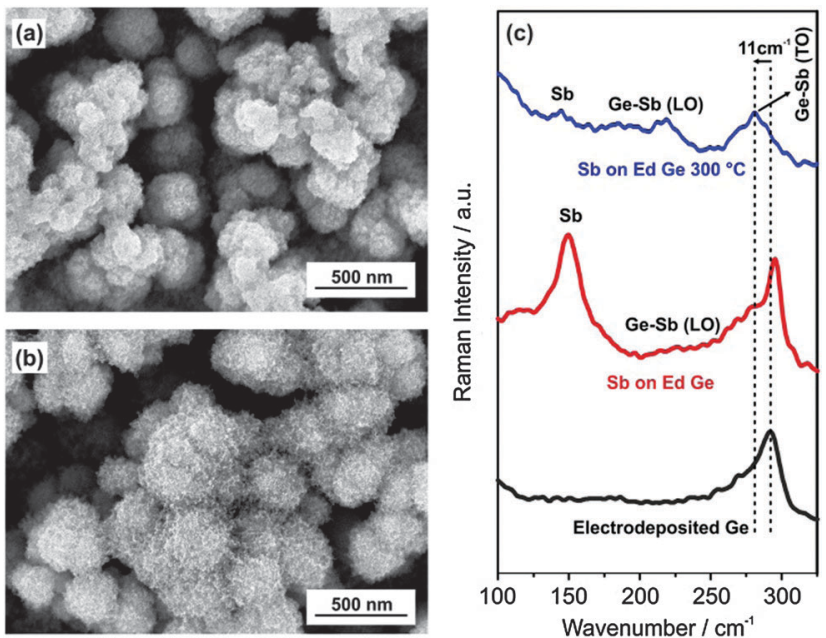

Fig. 1 (a) Microstructure of electrodeposited Ge; (b) SEM of electroless deposited $\mathrm{Sb}$ on $\mathrm{Ge}$ from $0.1 \mathrm{M} \mathrm{SbCl}_{3}-\left[\mathrm{Py}_{1,4}\right] \mathrm{TFSI}$; (c) Raman spectra of electrodeposited $\mathrm{Ge}$ (black line), electroless deposited $\mathrm{Sb}$ on Ge (red line) and after annealing to $300{ }^{\circ} \mathrm{C}$ (blue line).

to the SEM and the presence of some remaining ionic liquids, respectively. Upon modification of the electrodeposited Ge, the presence of $\mathrm{Sb}$ nanoparticles on the Ge clusters is evident, Fig. 1b. The EDX spectra (Fig. S2b, ESI $\dagger$ ) show prominent peaks of $\mathrm{Ge}$ and $\mathrm{Sb}$ confirming that electroless deposition occurred and led to surface modification of Ge. X-ray photoelectron spectroscopy (XPS) was also used to probe the surface composition before and after surface modification. The survey scan (Fig. S3, ESI $\dagger$ ) of Sb modified Ge shows contributions of both germanium and antimony along with carbon and chlorine in the surface layer. Peak fitting of the Ge $3 \mathrm{~d}$ (Fig. S4a, ESI $\dagger$ ) shows a $\mathrm{Ge}^{0}$ component as well as contributions of $\mathrm{GeO}_{x}$. The XPS spectrum of the $\mathrm{Sb} 3 \mathrm{~d}$ structure (Fig. S4b, ESI $\dagger$ ) could distinguish the $\mathrm{Sb}_{3} 3 \mathrm{~d}_{5 / 2}$ structure and $\mathrm{O} 1 \mathrm{~s}$. Furthermore the peak fit showed $\mathrm{Sb}^{0}$ as well as $\mathrm{Sb}^{3+}$ and $\mathrm{Sb}^{5+}$ which might be related to $\mathrm{SbCl}_{3}$ and the native oxide layer of the deposit. Thus, from XPS, we can say that $\mathrm{Ge}_{x} \mathrm{Sb}_{1-x}$, or a mixture of Ge and $\mathrm{Sb}$ phases are present in the Sb modified Ge along with some remaining $\mathrm{SbCl}_{3}$, germanium and antimony oxides.

Raman spectroscopy was also used to evaluate the changes in the Ge nanostructures upon surface modification. In Fig. 1c, electrodeposited Ge shows a Raman peak at $293 \mathrm{~cm}^{-1}$ indicating the presence of amorphous Ge nanoparticles. Surface modification of electrodeposited Ge in $0.1 \mathrm{M} \mathrm{SbCl}_{3}-\left[\mathrm{Py}_{1,4}\right]$ TFSI for 10 minutes led to the formation of $\mathrm{Sb} \mathrm{A} 1 \mathrm{~g}$ vibration mode at $150 \mathrm{~cm}^{-1}$ and a broad peak at $225 \mathrm{~cm}^{-1}$ which relates to the longitudinal optical (LO) phonon vibration of $\mathrm{Ge}_{x} \mathrm{Sb}_{1-x} \cdot{ }^{24-26}$ Upon heat treatment of the sample to $300{ }^{\circ} \mathrm{C}$ in vacuum, it is evident from Fig. $1 \mathrm{c}$ that there is a shift in the Ge peak by $11 \mathrm{~cm}^{-1}$ and the LO phonon vibration peak becomes prominent which confirms the formation of $\mathrm{Ge}_{x} \mathrm{Sb}_{1-x}$.

Cyclic voltammetry (CV) of electrodeposited Ge in $1 \mathrm{M}$ sodium bis(fluorosulfonyl)amide/1-butyl-3-methylpyrrolidinium bis(fluorosulfonyl)amide (NaFSI-[Py $\left.\mathrm{Py}_{1,4}\right] \mathrm{FSI}$ ) is shown in Fig. 2a. In the first $\mathrm{CV}$ cycle, the formation of a solid electrolyte interface (SEI) is seen between $+1.5 \mathrm{~V}$ and $+0.5 \mathrm{~V} .{ }^{27}$ An increase in negative (a)

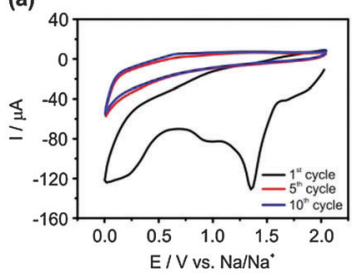

(c)

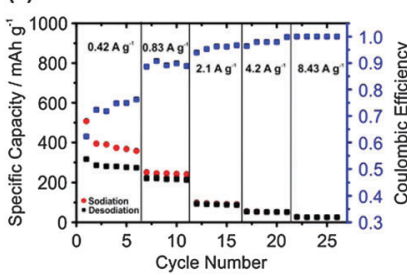

(b)

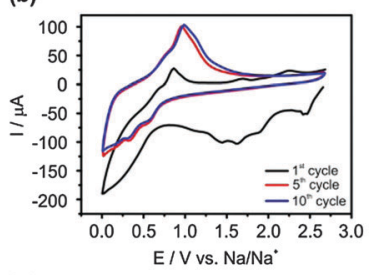

(d)

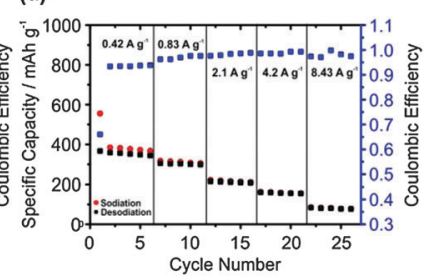

Fig. 2 (a) $\mathrm{CV}$ of electrodeposited Ge in $1 \mathrm{M} \mathrm{NaFSI}-\left[\mathrm{Py}_{1,4}\right] \mathrm{FSI}$ at a scan rate of $1 \mathrm{mV} \mathrm{s}^{-1}$; (b) CV of Sb modified Ge by electroless deposition, in $1 \mathrm{M}$ $\mathrm{NaFSI}-\left[\mathrm{Py}_{1,4}\right] \mathrm{FSI}$ at a scan rate of $1 \mathrm{mV} \mathrm{s}^{-1}$; (c and d) charge-discharge cycles at various current densities on electrodeposited Ge and Sb modified $\mathrm{Ge}$, respectively. The first charge-discharge cycle was run at $0.02 \mathrm{C}$ to form a stable SEI layer.

current is observed below $+0.5 \mathrm{~V}$ and can be related to the sodiation process. In the anodic scan, no desodiation process is observed. However, in the 5th and 10th CV scans, the sodiation process takes place below $+0.5 \mathrm{~V}$ during the cathodic scan, and a small desodiation wave is observed in the anodic scan at around $+0.65 \mathrm{~V}$. This is in contrast to that observed on Ge nanowires with an organic electrolyte wherein no desodiation peaks were observed in the $\mathrm{CV}$ cycles. ${ }^{27}$ The $\mathrm{CV}$ cycles on Sb surface modified Ge are shown in Fig. 2b. In the first cycle, the broad reduction peak between $+2.5 \mathrm{~V}$ and $+1.0 \mathrm{~V}$ represents the formation of the SEI layer. The sodiation process starts at $+0.7 \mathrm{~V}$, which is more positive potential compared to Ge. In the anodic scan, a shoulder is observed at around $+0.65 \mathrm{~V}$ and a peak is formed at $+0.86 \mathrm{~V}$, which can be associated with the desodiation process from Ge and $\mathrm{Ge}_{x} \mathrm{Sb}_{1-x}$, respectively. In the 5th and 10 th CV cycles, only the sodiation and desodiation processes are seen below $+0.75 \mathrm{~V}$ and above $+0.5 \mathrm{~V}$, respectively.

The galvanostatic charge-discharge processes at different current densities on electrodeposited Ge are shown in Fig. 2c. It is evident that at $0.42 \mathrm{~A} \mathrm{~g}^{-1}(1 \mathrm{C})$, the specific capacity of sodiation for the first five cycles gives an average value of $376 \mathrm{~mA} \mathrm{~h} \mathrm{~g}^{-1}$, which is in good agreement with the theoretical capacity for the formation of NaGe. ${ }^{14}$ Upon charging and discharging at higher rates, the specific capacity drops significantly, especially at 4.2 (10C) and $8.43 \mathrm{~A} \mathrm{~g}^{-1}$ (20C) wherein the specific capacity is 52 and $25 \mathrm{~mA} \mathrm{~h} \mathrm{~g}{ }^{-1}$, respectively. The increase in coulombic efficiency with a decreased specific capacity indicates that at high chargedischarge rates, the diffusion of $\mathrm{Na}$ is limited only to the surface of Ge without any sodiation to the bulk structure. In comparison, on Sb surface modified Ge, it is evident in Fig. $2 \mathrm{~d}$ that the specific capacity is significantly higher at 4.2 and $8.43 \mathrm{~A} \mathrm{~g}^{-1}$ with an average value of $160 \mathrm{~mA} \mathrm{~h} \mathrm{~g}^{-1}$ and $81 \mathrm{~mA} \mathrm{~h} \mathrm{~g}^{-1}$, respectively, which is an increase of more than $300 \%$ in Na storage. At a chargedischarge current of $0.83 \mathrm{~A} \mathrm{~g}^{-1}$, the specific capacity increased from 
$220 \mathrm{~mA} \mathrm{~h} \mathrm{~g}^{-1}$ for electrodeposited Ge to $310 \mathrm{~mA} \mathrm{~h} \mathrm{~g}{ }^{-1}$ on $\mathrm{Sb}$ modified Ge, which is an increase of about $40 \%$ in Na storage. However, not much of a difference is observed in Na storage at $0.42 \mathrm{~A} \mathrm{~g}^{-1}$. In comparison, the coulombic efficiency is higher in $\mathrm{Sb}$ modified $\mathrm{Ge}$ at $0.42 \mathrm{~A} \mathrm{~g}^{-1}$, which indicates that the diffusion of $\mathrm{Na}$ is more prominent and therefore at higher charge-discharge currents, a high capacity is achieved compared to Ge. The solidstate diffusion coefficient of $\mathrm{Na}$ in Ge is $10^{-13} \mathrm{~cm}^{2} \mathrm{~s}^{-1}$ and is about five orders higher in $\mathrm{Sb}$ where it is $10^{-8} \mathrm{~cm}^{2} \mathrm{~s}^{-1} \cdot \cdot^{27,28}$ As Ge is modified with $\mathrm{Sb}$ nanoparticles and $\mathrm{Ge}_{x} \mathrm{Sb}_{1-x}$ forms at the interface, the diffusion of $\mathrm{Na}$ can take place faster and can intercalate to the bulk of the deposit. To clarify this, galvanostatic chargedischarge cycles were performed on both electrodeposited Ge and $\mathrm{Sb}$ modified Ge.

Fig. 3a and b show the charge-discharge profiles of 2nd, 10th and 50th cycles. As repeatable results could not be achieved over 50 cycles for electrodeposited Ge at $0.83 \mathrm{~A} \mathrm{~g}^{-1}$, experiments were performed at $0.54 \mathrm{~A} \mathrm{~g}^{-1}(1.5 \mathrm{C})$.

For electrodeposited Ge, it is evident that the 2nd and 10th cycles show a specific capacity of about $180 \mathrm{~mA} \mathrm{~h} \mathrm{~g}{ }^{-1}$, which decreases to $140 \mathrm{~mA} \mathrm{~h} \mathrm{~g}^{-1}$ after the 50th cycle. This stability is much superior compared to the previously reported results with Ge thin films which showed degradation to almost zero capacity after 30 cycles at a much lower charge-discharge rate $(0.1 \mathrm{C}) .{ }^{14,15}$

In comparison, for the $\mathrm{Sb}$ modified Ge surface the specific capacity is $290 \mathrm{~mA} \mathrm{~h} \mathrm{~g}^{-1}$ for the first cycle and drops to $225 \mathrm{~mA} \mathrm{~h} \mathrm{~g}^{-1}$ after the 50th cycle at a charge-discharge current of $0.83 \mathrm{~A} \mathrm{~g}^{-1}$. Fig. 3c shows the comparison of the chargedischarge processes over 50 cycles for electrodeposited Ge and $\mathrm{Sb}$ modified Ge.

Although a higher current density is applied for $\mathrm{Sb}$ modified Ge compared to electrodeposited Ge, the specific capacity is higher by at least $50 \%$. In general, with a higher charge-discharge current, the specific capacity decreases. This improvement in the
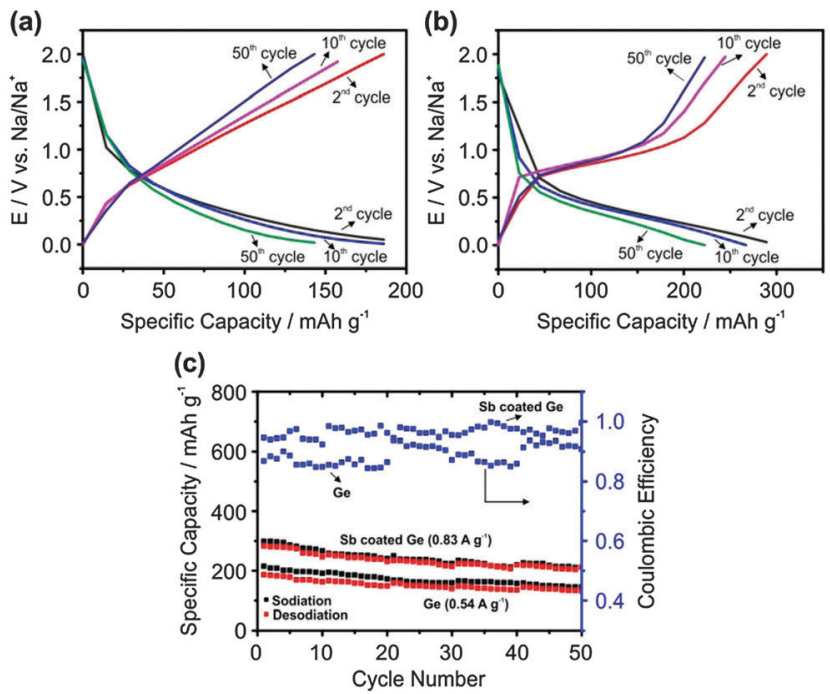

Fig. 3 Charge discharge curves for 2nd, 10th and 50th cycles for (a) electrodeposited Ge at $0.54 \mathrm{~A} \mathrm{~g}^{-1}$; (b) Sb modified Ge at $0.83 \mathrm{~A} \mathrm{~g}^{-1}$; (c) 50 chargedischarge cycles of electrodeposited $\mathrm{Ge}$ and $\mathrm{Sb}$ modified $\mathrm{Ge}$. The first charge-discharge cycle was run at $0.02 \mathrm{C}$ to form a stable SEl layer. specific capacity as well as higher coulombic efficiency for the $\mathrm{Sb}$ modified Ge compared to electrodeposited Ge can be related to the better diffusion of $\mathrm{Na}$ ions and the stable formation of the SEI layer.

To evaluate the stability of the SEI layer formed as well as to understand the diffusion of $\mathrm{Na}$ ions in $\mathrm{Sb}$ modified $\mathrm{Ge}$, X-ray photoelectron spectroscopy (XPS) and Auger electron spectroscopy (AES) were employed. The cycled samples were initially etched by $\mathrm{Ar}^{+}$ions accelerated to $1 \mathrm{keV}$ in order to remove any residual ionic liquid from the top layer of the surface. The survey spectrum (see Fig. S5, ESI $\dagger$ ) compares the cycled samples to the uncycled ones wherein additional peaks of sodium and sulphur are seen for the cycled samples. Fig. 4a-c shows the detailed spectra of $\mathrm{Na} 1 \mathrm{~s}, \mathrm{~F}$ 1s and $S 2 p$ transitions for the $\mathrm{Sb}$ surface modified germanium (red line) and germanium sample (black line) after cycling.

The symmetric peak shape of $\mathrm{Na} 1 \mathrm{~s}$ in Fig. 4a indicates sodium compounds, rather than metallic sodium, and is emphasized by a prominent $\mathrm{NaF}^{29}$ peak at $685.6 \mathrm{eV}$ binding energy (BE) in the $\mathrm{F}$ 1s detail spectrum (Fig. 4b). The sodiated Ge additionally shows contributions from FSI at $689.4 \mathrm{eV} \mathrm{BE}$. Contributions of FSI could be observed for the Sb modified Ge sample, too. However, a significant difference in the S 2p spectrum is observed upon comparing the sodiation process in $\mathrm{Ge}$ and $\mathrm{Sb}$ modified Ge. The $\mathrm{S} 2$ p spectrum in Fig. 4c reveals a shoulder at $165.3 \mathrm{eV} \mathrm{BE}$ for the Ge sample and a peak at $162.8 \mathrm{eV} \mathrm{BE}$. The peak at $162.8 \mathrm{eV} \mathrm{BE}$ can be assigned to sodium sulphide ${ }^{30}$ and the shoulder at $165.3 \mathrm{eV} \mathrm{BE}$ is most likely sodium sulphate which might have

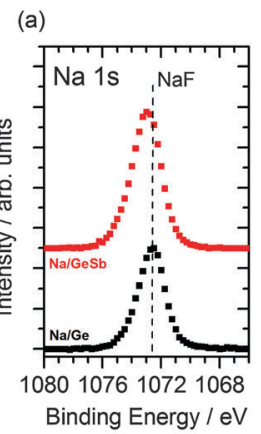

(b)

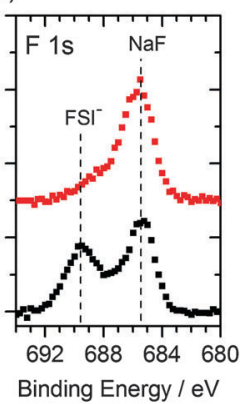

(c)

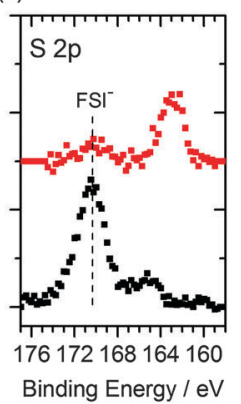

(d)

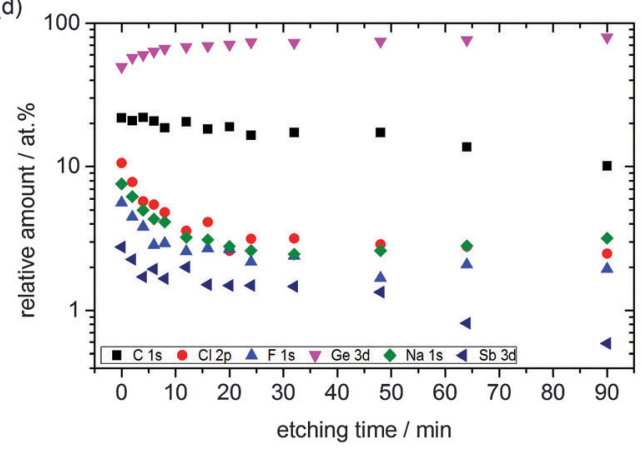

Fig. 4 (a-c) XPS detailed spectra ( $\mathrm{Na} 1 \mathrm{~s}, \mathrm{~F}$ 1s and S 2p) of electrodeposited $\mathrm{Ge}$ (black) and $\mathrm{Sb}$ modified $\mathrm{Ge}$ (red) after 50 charge-discharge cycles in $1 \mathrm{M} \mathrm{NaFSI}-\left[\mathrm{Py}_{1,4}\right] \mathrm{FSI}$; (d) stoichiometry of surface components from XPS survey spectra after sputter etching with $2 \mathrm{keV} \mathrm{Ar}^{+}$ions for $\mathrm{Sb}$ modified Ge sample after cycling. 
formed due to the reduction of FSI in the presence of sodium ions. ${ }^{31}$ Upon analysing the Sb spectra (Fig. S6, ESI $\dagger$ ) before and after cycling, a significant difference is observed. The $\mathrm{Sb}^{3+}$ and $\mathrm{Sb}^{5+}$ peaks have diminished along with $\mathrm{Sb} 3 \mathrm{~d}_{3 / 2}$ and a clear $\mathrm{Na}$ KLL and $O$ 1s peak can be distinguished. This suggests that a relatively thick SEI layer is formed and $\mathrm{Na}$ has intercalated into the $\mathrm{Sb}$ layer and probably reduces the oxide species of $\mathrm{Sb}$ during intercalation. The presence of $\mathrm{O} 1 \mathrm{~s}$ could be due to the formation of $\mathrm{Na}_{2} \mathrm{O}$. A similar reduction process was seen during $\mathrm{Na}$ intercalation in $\mathrm{TiO}_{2}{ }^{32}$

Subsequently the cycled antimony modified Ge sample was

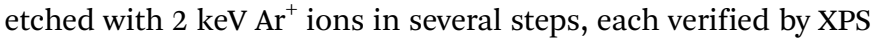
survey spectra. The peak areas were normalized by photoelectric cross-sections, asymmetry factors and transmission functions of the hemispherical analyzer to calculate the stoichiometry of the surface components. Although the actual sputter rate depends on various effects (on the matrix and molecular level) the stoichiometric data were plotted against sputter time in Fig. 4d to give a semi-quantitative insight of the composition with depth. It is evident that the relative amount of germanium increases within the first 20 minutes of etching, whereas that of the other components like carbon, chlorine, fluorine, antimony and sodium decreases. Between 20 and 50 minutes of sputtering, the Na concentration plateaus and slightly increases upon further sputtering, whereas $\mathrm{Sb}$ concentration decreases significantly after 50 minutes of sputtering. This indicates that Na not only has intercalated to the outer layers, but also has intercalated to the bulk of Ge.

Further investigation of the SEI layer after the first sodiation process showed the formation of a thin inorganic SEI layer on the $\mathrm{Sb}$ modified Ge and an organic outer layer. A large area image showing the formation of the SEI layer is shown in Fig. S7 (ESI $\dagger$ ). Fig. 5a shows the SEM image of Sb modified Ge after the first full charge. The image reveals two different structured deposits, a thick cauliflower-like deposit (A) and a comparatively thin layer (B). The respective Auger electron spectroscopy (AES) data are shown in Fig. 5b. While both spectra show distinctive peaks, which can be assigned to sulphur (S LMM), chlorine (Cl LMM), carbon (C KLL), oxygen (O KLL) and fluorine (F KLL); significant amounts of antimony ( $\mathrm{Sb}$ MNN), germanium (Ge LMM) and sodium ( $\mathrm{Na} \mathrm{KLL}$ ) can only be found for the thin layer (B). The formation of the inorganic-organic SEI layers has been shown to be advantageous for $\mathrm{Li}$-air batteries wherein the $\mathrm{Li}$ dendritic growth could be avoided, thereby resulting in an enhanced coulombic efficiency. ${ }^{33}$

Thus, from the XPS and AES results, it appears that on $\mathrm{Sb}$ modified Ge, a better SEI layer is formed which is made up of primarily sodium compounds $\left(\mathrm{NaF}, \mathrm{Na}_{2} \mathrm{~S}\right)$ in the inner layer compared to the presence of higher concentrations of decomposed ionic liquids along with sodium compounds for Ge. The presence of sodium compounds would result in faster sodium diffusion through the SEI layer, whereas the outer organic SEI layer protects the electrode from further reacting with the electrolyte during the charge-discharge processes. Also, as $\mathrm{Ge}_{x} \mathrm{Sb}_{1-x}$ is formed (shown by Raman spectroscopy) on the Sb modified Ge surface, it might have created defects in the Ge structure during

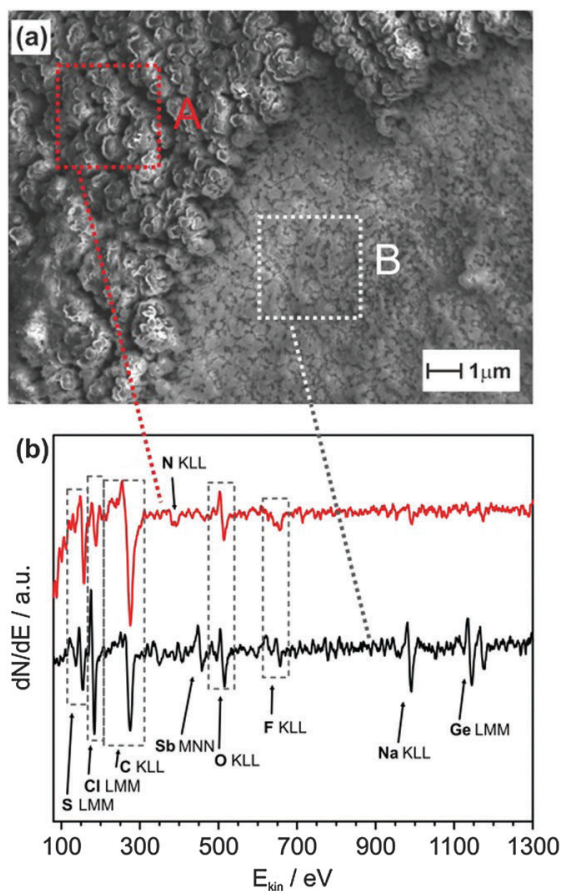

Fig. 5 (a) SEM image of Sb modified Ge after the first sodiation process recorded at a beam energy of $5 \mathrm{kV}$; (b) AES spectra of the regions marked in the SEM image.

galvanic displacement reaction, resulting in faster diffusion of $\mathrm{Na}$ ions in Ge as exemplified by the depth profile analysis in Fig. 4d. These two factors have resulted in improved charge storage and battery performance at higher charge densities for $\mathrm{Sb}$ modified Ge.

\section{Conclusions}

In conclusion, we have demonstrated a versatile technique of surface modification of a germanium electrode using electroless deposition from ionic liquids at room temperature. The surface modification led to improved capacity and stability of the Na-ion batteries at high charge/discharge current densities with an ionic liquid electrolyte. The present findings open up new paradigms for creating and modifying anodic materials for rechargeable batteries.

\section{Acknowledgements}

The authors would like to thank Mrs Karin Bode, Institute of Inorganic Chemistry (Prof. A. Adam) for help with Raman measurements and Prof. W. Daum for providing the NanoSAM (Omicron NanoSAM provided by: Deutsche Forschungsgesellschaft DFG, grant number: INST 189/158-1). The authors would also like to thank Celgard for providing the membrane.

\section{Notes and references}

1 H. Pan, Y.-S. Hu and L. Chen, Energy Environ. Sci., 2013, 6, 2338.

2 N. Yabuuchi, K. Kubota, M. Dahbi and S. Komaba, Chem. Rev., 2014, 114, 11636. 
3 D. Kundu, E. Talaie, V. Duffort and L. F. Nazar, Angew. Chem., Int. Ed., 2015, 54, 3431.

4 Y. Kim, K.-H. Ha, S. M. Oh and K. T. Lee, Chem. - Eur. J., 2014, 20, 11980.

5 M. Dahbi, N. Yabuuchi, K. Kubota, K. Tokiwa and S. Komaba, Phys. Chem. Chem. Phys., 2014, 16, 15007.

6 Z. Li, J. Ding and D. Mitlin, Acc. Chem. Res., 2015, 48, 1657.

7 H. Kang, Y. Liu, K. Cao, Y. Zhao, L. Jiao, Y. Wang and H. Yuan, J. Mater. Chem. A, 2015, 3, 17899.

8 B. Farbod, K. Cui, W. P. Kalisvaart, M. Kupsta, B. Zahiri, A. Kohandehghan, E. M. Lotfabad, Z. Li, E. J. Luber and D. Mitlin, ACS Nano, 2014, 8, 4415.

9 P. R. Abel, M. G. Fields, A. Heller and C. B. Mullins, ACS Appl. Mater. Interfaces, 2014, 6, 15860.

10 J. Hur and I. T. Kim, Bull. Korean Chem. Soc., 2015, 36, 1625.

11 N. Lin, J. Zhou, Y. Han, K. Zhang, Y. Zhu and Y. Qian, Chem. Commun., 2015, 51, 17156.

12 Y. Xu, X. Zhu, X. Zhou, X. Liu, Y. Liu, Z. Dai and J. Bao, J. Phys. Chem. C, 2014, 118, 28502.

13 L. Hu, X. Zhu, Y. Du, Y. Li, X. Zhou and J. Bao, Chem. Mater., 2015, 27, 8138.

14 L. Baggetto, J. K. Keum, J. F. Browning and G. M. Veith, Electrochem. Commun., 2013, 34, 41.

15 P. R. Abel, Y.-M. Lin, T. de Souza, C.-Y. Chou, A. Gupta, J. B. Goodenough, G. S. Hwang, A. Heller and C. B. Mullins, J. Phys. Chem. C, 2013, 117, 18885.

16 T.-F. Yi, Y.-R. Zhu, X.-D. Zhu, J. Shu, C.-B. Yue and A.-N. Zhou, Ionics, 2009, 15, 779.

17 A. Mauger and C. Julien, Ionics, 2014, 20, 751.

18 L. J. Fu, H. Liu, C. Li, Y. P. Wu, E. Rahm, R. Holze and H. Q. Wu, Solid State Sci., 2006, 8, 113.
19 K.-X. Wang, X.-H. Li and J.-S. Chen, Adv. Mater., 2015, 27, 527.

20 J. W. Kim, J. H. Ryu, K. T. Lee and S. M. Oh, J. Power Sources, 2006, 147, 227.

21 M. Thakur, M. Isaacson, S. L. Sinsabaugh, M. S. Wong and L. J. Biswal, J. Power Sources, 2012, 205, 426.

22 W. McSweeney, H. Geaney and C. O'Dwyer, Nano Res., 2015, 8, 1395.

23 A. Lahiri, S. Zein El Abedin and F. Endres, J. Phys. Chem. C, 2012, 116, 17739.

24 C. C. Huang, B. Gholipour, K. Knight, J. Y. Ou and D. W. Hewak, Adv. OptoElectron., 2012, 840348, 1.

25 Q. H. F. Rebelo, E. A. Cotta, S. M. de Souza, D. M. Trichês, K. D. Machado, J. C. de Lima, T. A. Grandi, C. M. Poffo and L. Manzato, J. Alloys Compd., 2013, 575, 80.

26 T. Nakagawa, K. Ohta and N. Koshizuka, Jpn. J. Appl. Phys., 1980, 19, L339.

27 A. Kohandehghan, K. Cui, M. Kupsta, J. Ding, E. M. Lotfabad, W. P. Kalisvaart and D. Mitlin, Nano Lett., 2014, 14, 5873.

28 L. Baggetto, P. Ganesh, C.-N. Sun, R. A. Meisner, T. A. Zawodzinski and G. M. Veith, J. Mater. Chem. A, 2013, 1, 7985.

29 W. E. Morgan, J. R. Van Wazer and W. J. Stec, J. Am. Chem. Soc., 1973, 95, 751.

30 K. M. Abraham and S. M. Chaudhri, J. Electrochem. Soc., 1986, 133, 1307.

31 S. Xiong, S. K. Xie, E. Blomberg, P. Jacobsson and A. Matic, J. Power Sources, 2014, 252, 150.

32 L. Wu, D. Bresser, D. Buchholz, G. A. Giffin, C. R. Castro, A. Ochel and S. Passerini, Adv. Energy Mater., 2015, 5, 1401142.

33 X.-B. Cheng, R. Zhang, C.-Z. Zhao, F. Wei, J.-G. Zhang and Q. Zhang, Adv. Sci., 2016, 3, 1500213. 